\title{
Interleukin-6 gene (IL-6): a possible role in brain morphology in the healthy adult brain
}

\author{
Bernhard T Baune ${ }^{1 *}$, Carsten Konrad ${ }^{2}$, Dominik Grotegerd ${ }^{3}$, Thomas Suslow ${ }^{3,5}$, Eva Birosova ${ }^{6}$, Patricia Ohrmann ${ }^{3}$, \\ Jochen Bauer ${ }^{3}$, Volker Arolt ${ }^{3}$, Walter Heindel ${ }^{7}$, Katharina Domschke ${ }^{3,4}$, Sonja Schöning ${ }^{3}$, Astrid V Rauch ${ }^{3}$, \\ Christina UhImann ${ }^{3}$, Harald Kugel ${ }^{7}$ and Udo Dannlowski ${ }^{2,3}$
}

\begin{abstract}
Background: Cytokines such as interleukin 6 (IL-6) have been implicated in dual functions in neuropsychiatric disorders. Little is known about the genetic predisposition to neurodegenerative and neuroproliferative properties of cytokine genes. In this study the potential dual role of several IL-6 polymorphisms in brain morphology is investigated.

Methodology: In a large sample of healthy individuals $(N=303)$, associations between genetic variants of IL- 6 (rs1800795; rs1800796, rs2069833, rs2069840) and brain volume (gray matter volume) were analyzed using voxelbased morphometry (VBM). Selection of single nucleotide polymorphisms (SNPS) followed a tagging SNP approach (e.g., Stampa algorigthm), yielding a capture $97.08 \%$ of the variation in the IL-6 gene using four tagging SNPs. Principal findings/results

In a whole-brain analysis, the polymorphism rs1800795 (-174 C/G) showed a strong main effect of genotype (43 CC vs. 150 CG vs. $100 \mathrm{GG} ; x=24, y=-10, z=-15 ; F(2,286)=8.54$, puncorrected $=0.0002 ; p_{\text {Alphasim-corrected }}=0.002$; cluster size $k=577$ ) within the right hippocampus head. Homozygous carriers of the G-allele had significantly larger hippocampus gray matter volumes compared to heterozygous subjects. None of the other investigated SNPs showed a significant association with grey matter volume in whole-brain analyses.

Conclusions/significance: These findings suggest a possible neuroprotective role of the G-allele of the SNP rs1800795 on hippocampal volumes. Studies on the role of this SNP in psychiatric populations and especially in those with an affected hippocampus (e.g., by maltreatment, stress) are warranted.
\end{abstract}

Keywords: Genetics, Inflammation, Interleukin 6, Neuroprotection, Voxel-based morphometry

\section{Introduction}

Inflammation is implicated in the etiology and pathophysiology of several brain pathologies (e.g., major depression [1-3], Alzheimer's disease [4], and post-stroke depression [5]), as well as in cognitive aging [6] and mortality [7]. Specific markers of systemic inflammation such as cytokines have been identified as important mediators of neurodegenerative [8] and neuroplastic [9,10] processes relevant to neuropsychiatric disorders. Some of these proteins (e.g., interleukin 1 beta, interleukin 6, tumor necrosis factor) play a critical role in physiological CNS processes,

\footnotetext{
* Correspondence: bernhard.baune@adelaide.edu.au

'Discipline of Psychiatry, School of Medicine, University of Adelaide, North

Terrace, Adelaide, South Australia 5005, Australia

Full list of author information is available at the end of the article
}

such as cognitive function under immunologically unchallenged conditions $[2,6]$.

Interleukin 6 (IL-6) is a cytokine that has demonstrated both neurodegenerative [4] and neuroprotective [11,12] properties. For example, increased levels of IL-6 are associated with neuropsychiatric conditions, such as depression [13] and Alzheimer's disease [14]. In addition, first studies on the association between IL- 6 and brain volume suggested a role of increased serum levels of IL- 6 in brain atrophy during normal aging in conjunction with other cytokines [15]. In addition, an association between IL-6 levels and decreased hippocampal gray matter volume in middle-aged adults has recently been reported [16].

However, the hypothesis that IL-6 is mainly proinflammatory and neurodegenerative is challenged [17] with

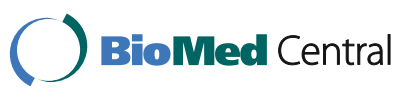


results supporting that this cytokine has several antiinflammatory and immunosuppressive activities that may play a downregulating role in inflammatory conditions [17]. In addition, IL-6 may act as a developmental neurotrophic factor $[18,19]$, and it has been shown to improve survival in vitro of several classes of neurons [20-22]. Moreover, it is suggested that IL-6 predominantly plays a protective role by improving survival of neurons in culture $[21,23,24]$, protecting neurons from excitotoxic and ischemic insults [25-28], and promoting the growth of axons and consequently the number of synapses in a region [29-32]. Additionally, evidence shows that IL-6 may play a major role in promoting synaptic plasticity, LTP, and memory consolidation [33-35]. Furthermore, IL-6 is found to regulate survival of differentiated neurons and the development of astrocytes $[36,37]$. Overall, these findings from previous studies suggest that higher IL-6 levels may play a dual role with both neurodegenerative and neuroprotective biological functions.

The current evidence in humans relies on measures of IL-6 in serum and CSF, whereas limited research on the influence of genetic variants of IL-6 on brain pathology has been published. The $I L-6$ gene is located on chromosome $7 \mathrm{p} 21$, and the GG genotype of the frequently studied IL-6 promoter $-174 \mathrm{C} / \mathrm{G}$ variation relates to higher levels of IL-6 compared to the CC genotype [38]. Although this single nucleotide polymorphism (SNP) has received a lot of attention in research in aging and longevity, the findings are inconclusively showing an association between the numbers of $\mathrm{G}$ alleles either with increased [39] or decreased [38] longevity depending on the study design, ethnicity, lifestyle, and cultural differences. Additional single nucleotide polymorphisms (SNPs), such as rs1800796, influence IL-6 expression (G allele carriers increase IL-6 plasma levels) [40] and are influenced by the presence of other polymorphisms (e.g., rs2069833, rs2069840) at this chromosomal locus [41]. However, these other genetic variants of $I L-6$ have hardly been studied in brain function yet.
Further clarification of the biological role of genetic variants of $I L-6$ in the human brain is needed to describe its multifunctional effects. In this study, we investigate the role of the $I L-6$ gene in brain function and brain morphology by investigating the association between several genetic variants of interleukin 6 and brain morphology in healthy adult individuals. While this analysis is conducted in a whole-brain fashion, we expect genetic effects particularly in the hippocampus (HC) since this brain region has a critical role in normal brain function and several neuropsychiatric disorders. The HC region is a highly important structure for memory consolidation, and it has shown a strong susceptibility to stress and response to cytokines [42]. Specifically, several studies have shown that depression, post-traumatic stress disorder (PTSD), and childhood maltreatment are associated with smaller hippocampal volumes [42-44]. The role of genetic inflammatory biomarkers, such as IL-6, in these relationships is unclear.

This study aims at an improved understanding of the genetic background of the dual role of IL-6 in brain morphology and the hippocampal structure in particular. We hypothesize that IL-6 polymorphisms are related to brain gray matter volumes, specifically in the hippocampus. The analysis will inform future studies in clinical psychiatric populations on the possible role and selection of genetic variants of $I L-6$ for the study of hippocampal function in neuropsychiatric disorders.

\section{Material and methods}

Subjects. Healthy subjects $(N=303)$ aged $18-65$ of Central European ancestry participated in the study. Data were pooled from various studies conducted at the Department of Psychiatry, University of Münster, Germany, all employing the same MRI sequence on the same scanner. All included subjects were thoroughly investigated by experienced psychologists and were free from any lifetime history of psychiatric disorders according to DSM-IV criteria [45], as diagnosed with the SCID interview [46]. Exclusion criteria were scores $\geq 10$ on the Beck

Table 1 Selection of single nucleotide polymorphisms within IL-6 gene

\begin{tabular}{|c|c|c|c|c|c|c|c|c|c|c|c|}
\hline Gene & $\begin{array}{l}\text { Gene } \\
\text { position }\end{array}$ & $\begin{array}{l}\text { Total } \\
\text { no. of } \\
\text { SNPs } \\
\text { (MAF } \\
\geq 0.01 \text { ) }\end{array}$ & $\begin{array}{l}\text { No. of } \\
\text { tagging } \\
\text { SNP }\end{array}$ & $\begin{array}{l}\text { Mean } \\
r^{2}\end{array}$ & $\begin{array}{l}\text { Selected } \\
\text { SNPs }\end{array}$ & Position & Function & Alleles & $\begin{array}{l}\text { MAF } \\
\text { HapMapCEU }\end{array}$ & $\begin{array}{l}\text { Alleles } \\
\text { captured }\end{array}$ & $\begin{array}{l}\text { Prediction } \\
\text { (STAMPA) }\end{array}$ \\
\hline \multirow[t]{4}{*}{ IL-6 } & \multirow{4}{*}{$\begin{array}{l}\text { chr7: } \\
22,731,750- \\
22,738,790\end{array}$} & \multirow[t]{4}{*}{43} & \multirow[t]{4}{*}{22} & \multirow[t]{4}{*}{0.991} & rs1800795 & 22733170 & $\begin{array}{l}\text { 5' near } \\
\text { gene }\end{array}$ & $C G$ & $0.467(\mathrm{G})$ & 8 & \multirow[t]{4}{*}{$97.08 \%$} \\
\hline & & & & & rs1800796 & 22732771 & $\begin{array}{l}5 ' \text { near } \\
\text { gene }\end{array}$ & $C G$ & $0.043(C)$ & 3 & \\
\hline & & & & & rs2069833 & 22734189 & intron & $C T$ & $0.475(\mathrm{~T})$ & 8 & \\
\hline & & & & & rs2069840 & 22735097 & intron & CG & $0.317(\mathrm{G})$ & 1 & \\
\hline
\end{tabular}

SNP, single nucleotide polymorphism; MAF, minor allele frequency; $r^{2}$, linkage disequilibrium statistic [49]. MAF data relates CEU population from HapMap Phase II + III [50]. 
Depression Inventory (BDI) [47], any neurological abnormalities, history of seizures, head trauma or unconsciousness, intake of any psychotropic medication, and the usual MRI contraindications. Six subjects had to be excluded because of anatomical abnormalities (abnormally enlarged ventricles) or strong movement artifacts discovered in the structural MRI images checked by visual inspection and identification as extreme outliers in the check data quality function of the VBM8 Toolbox. The remaining $N=297$ scans (mean age 33.4 \pm 11.7 ; $N=124$ men, $N=173$ women) were clear of such problems. Verbal intelligence was estimated by the Mehrfachwahl-Wortschatz-Intelligenztest (multiple-choice vocabulary intelligence test; MWT-B) [48]. See Table 1 for sample characteristics. The study was approved by the Ethics Committee of the University of Münster. After complete description of the study to the participants, written informed consent was obtained.

\section{Selection of polymorphisms and genotyping}

The presently analyzed sequence of the $I L-6$ gene comprising about $4.8 \mathrm{~kb}$. We investigated genetic polymorphisms within this region as well as neighboring 5'and 3'- segments containing possible gene regulatory elements including positions between 22,731,750 and $22,738,790$ at chromosome 7 p21. The investigated region contains 43 single nucleotide polymorphisms (SNPs) [50]. Applying a tagging SNP approach, we used various techniques to limit the number of SNPs assessed to the most relevant as follows. Initially, we constructed the linkage disequilibrium (LD) pattern of the CEPH population of the HapMap Phase II genotype data to identify tagging SNPs by an aggressive tagging approach (MAF $>1 \%$ and $\left.r^{2}>0.8\right)$ using the Gevalt v2 software package [51]. Subsequently, we reduced SNP numbers by assessing the ability of limited numbers of the tagging SNPs to predict the total SNP population using the Stampa algorithm [52]. With this approach, $97.08 \%$ of the variation in the gene was captured using four tagging SNPs (rs1800795; rs1800796; rs2069833; rs2069840). The mean $\mathrm{r}^{2}$ of individual tagging SNPs in conjunction with one or more tagged SNPs was 0.991 (see Table 2 for details). While the SNPs rs1800795 and rs1800796 have been shown to directly regulate IL-6 expression, the other two SNPs (rs2069833, rs2069840) are non-coding variants [53]. The $G$ allele of marker rs2069840 has shown to be associated with lower IL-6 plasma concentrations under a dominant model in a recently published cohort study [54].

Genotyping of four tagging $I L-6$ SNPs was carried out following published protocols applying the multiplex genotyping assay iPLEX ${ }^{\mathrm{TM}}$ for use with the MassARRAY platform [55], yielding an overall genotyping completion rate of $98.9 \%$ [4/297 genotyping failures for rs1800795
Table 2 Sample characteristics dependent on IL-6 -174 C/ G genotype

\begin{tabular}{llll}
$\begin{array}{l}\text { CC } \\
(N=43)\end{array}$ & $\begin{array}{l}\text { CG } \\
(\boldsymbol{N}=\mathbf{1 5 0})\end{array}$ & $\begin{array}{l}\text { GG } \\
(\boldsymbol{N = 1 0 0})\end{array}$ & $\begin{array}{l}\text { p-value, } \\
\text { according to } \mathrm{X}^{\mathbf{2}}- \\
\text { test } \\
(\mathbf{d f}=\mathbf{2}) \text { or } \\
\text { ANOVA }\left(\mathbf{F}_{2,290}\right)\end{array}$ \\
\hline $34.6 \pm 12.3$ & $34.0 \pm 12.3$ & $31.8 \pm 10.4$ & 0.25 \\
\hline $19 / 24$ & $61 / 89$ & $42 / 58$ & 0.92 \\
\hline $119.1 \pm 13.8$ & $118.3 \pm 12.1$ & $118.1 \pm 11.9$ & 0.92 \\
\hline $15.0 \pm 2.4$ & $14.8 \pm 2.1$ & $14.7 \pm 2.1$ & 0.82 \\
\hline $31.0 \pm 6.7$ & $32.8 \pm 6.3$ & $32.3 \pm 6.8$ & 0.32 \\
\hline $2.2 \pm 3.0$ & $2.3 \pm 2.7$ & $2.4 \pm 2.9$ & 0.93 \\
\hline
\end{tabular}

${ }^{1}$ Assessed with the Mehrfachwahl-Wortschatz test (multiple-choice vocabulary test; Lehrl, 1995), data from $N=230$ subjects available. ${ }^{2}$ State-Trait Anxiety Inventory, data from $N=258$ subjects available. ${ }^{3}$ Beck Depression Inventory, data from $N=283$ subjects available.

and rs2069833 (99.0\%), 5/297 for rs1800796 and rs2069840 (98.7\%)]. Genotypes were determined by investigators blinded for the study.

Hardy-Weinberg equilibrium was fulfilled for all four SNPs, according to the program Finetti provided as an online source (http://ihg.gsf.de/cgi-bin/hw/hwa1.pl; Wienker TF and Strom TM) (exact test: rs1800795, $p=0.33 ; \quad$ rs1800796, $\quad p=1 ; \quad$ rs2069833, $\quad p=0.33$; rs2069840, $p=0.80)$.

\section{MRI methods}

Voxel-based morphometry: T1-weighted high-resolution anatomical images were acquired on a 3-Tesla scanner (Gyroscan Intera $3 \mathrm{~T}$, Philips Medical Systems, Best, The Netherlands) with a 3D fast gradient echo sequence (Turbo Field Echo, TFE), TR=7.4 ms, TE $3.4 \mathrm{~ms}, \mathrm{FA}=$ $9^{\circ}$, two signal averages, inversion prepulse every $814.5 \mathrm{~ms}$, acquired over a field of view of $256(\mathrm{FH}) \times 204$ $(\mathrm{AP}) \times 160(\mathrm{RL}) \mathrm{mm}$, phase encoding in AP and RL direction, reconstructed to cubic voxels of $0.5 \mathrm{~mm} \times 0.5$ $\mathrm{mm} \times 0.5 \mathrm{~mm}$. The VBM8 toolbox (version 419; http:// $\mathrm{dbm}$.neuro.uni-jena.de/vbm) was used for preprocessing the structural images with default parameters. Images were bias-corrected, tissue classified, and normalized to MNI-space using linear (12-parameter affine) and nonlinear transformations, within a unified model [56] including high-dimensional DARTEL normalization to the default DARTEL template provided with the VBM8 toolbox (resolution $1.5 \times 1.5 \times 1.5 \mathrm{~mm}$ ). Gray and white matter segments were modulated only by the non-linear components in order to preserve actual GM and WM values locally (modulated GM and WM volumes), which results in a correction for total brain volume.

Homogeneity of gray matter images was checked using the covariance structure of each image with all other images, as implemented in the check data quality 
function. As described above, six extreme outliers showing anatomical abnormalities or movement artifacts were identified and excluded. The modulated gray matter images were smoothed with a Gaussian kernel of 8-mm FWHW. Group statistics were calculated with second level models using SPM8. For each SNP a separate full factorial model was conducted using genotype as the between-subjects factor. Age, education, and gender were added to the model as nuisance regressors. There was an upgrade of the scanner gradient system in 2008 ("Master" Gradient System to "Quasar Dual" Gradient System). Although the MRI sequence remained identical before and after the gradient system upgrade, we additionally modeled the scanner upgrade as regressors of no interest.

To control for multiple statistical testing within the entire brain, we maintained a cluster-level false-positive detection rate at $p<0.05$ using a voxel-level threshold of $p<0.005$ with a cluster extent (k) empirically determined by Monte Carlo simulations ( $n=1,000$ iterations). This was performed by means of the AlphaSim procedure, which accounted for spatial correlations between BOLD signal changes in neighboring voxels [57], implemented in the REST toolbox (http://restfmri.net/forum/ index.php). The empirically determined cluster thresholds were $k=340$ voxels. The anatomical labeling for the whole-brain data was performed by means of the widely used AAL Toolbox [58] and additionally by means of the Anatomy Toolbox [59]. The present sample had sufficient power $(1-\beta=80 \%)$ to detect relatively small effect sizes in a three-group ANOVA $(\mathrm{f}=0.17)$ and in an alleledose regression $(r=0.14)$, as calculated with $G^{*}$ Power [60].

\section{Results}

rs1800795 (-174 C/G): The whole-brain analysis yielded a strong main effect of genotype [43 CC vs. $150 \mathrm{CG}$ vs. $100 \mathrm{GG}), \mathrm{x}=24, \mathrm{y}=-10, \mathrm{z}=-15 ; \mathrm{F}(2,286)=8.54$, puncorrected $=0.0002 ; \quad p_{\text {AlphaSim-corrected }}=0.002 ;$ cluster size $\mathrm{k}=577$, effect size $\mathrm{f}=0.23$ (Figure 1 )]. According to the automated anatomical labeling, this cluster was located in the right hippocampus head, extending to the parahippocampal gyrus and the dorsal parts of the right amygdala. The Anatomy toolbox yielded similar localizations (peak effect was found in the cornu ammonis and subiculum area, extending to the laterobasal amygdala). There were no other areas in the entire brain surviving our corrected statistical threshold. Repeating this analysis with smoothing kernels of $6 \mathrm{~mm}$ or $10 \mathrm{~mm}$ still would yield significant findings.

According to post-hoc t-contrasts, subjects homozygous for the G-allele had significantly larger hippocampal gray matter volumes compared to heterozygous subjects, $\mathrm{x}=24, \mathrm{y}=-10, \mathrm{z}=-15 ; \mathrm{t}(286)=3.88$, puncorrected
$<0.0001 ; \mathrm{p}_{\text {AlphaSim-corrected }}<0.001$; cluster size $\mathrm{k}=1210$. Again, there were no other brain regions surviving the statistical threshold. However, there were no significant differences between heterozygous subjects and CC carriers in this model. Nonetheless, testing for allele-dose effects via regressing the number of rs1800795 (-174 C/ G) G-alleles $(0,1,2)$ on whole brain gray matter volume (again, including age, gender, education, and scanner gradient system as nuisance regressors) also yielded a significant cluster at a similar location in the right hippocampus, $\mathrm{x}=21, \mathrm{y}=-12, \mathrm{z}=-15 ; \mathrm{t}(287)=3.82$, $\mathrm{p}_{\text {un- }}$ corrected $<0.0001 ; \quad p_{\text {AlphaSim-corrected }}=0.001$; cluster size $\mathrm{k}=853, \mathrm{r}=0.22$ (see Figure 1).

We further checked for interactions of the rs1800795 genotype and age as well as gender by modeling the interaction term in the three-group ANOVA model and the allele-dose regression. However, none of the interactions reached even a trend level of significance. Thus, the observed genotype effect on hippocampal gray matter volumes was comparable in men and women, and found across the entire age range.

rs1800796, rs2069833, rs2069840: No significant effects of these SNPs on hippocampus morphometry could be discerned in the whole-brain analysis.

\section{Discussion}

This imaging genetics study investigated the association between the $I L-6$ gene and brain morphology in a large cohort of healthy adult participants in a whole-brain analysis approach. Carriers of the G-allele of the $I L-6$ genetic variant $r s 1800795(-174 \mathrm{C} / \mathrm{G})$ showed a significant association with larger hippocampal volumes on the right side in healthy subjects. This genotype effect was remarkably specific to the hippocampus, with no other structure surviving our statistical threshold corrected for the entire brain. The findings are suggestive of a neuroprotective role of the IL-6 gene [rs1800795 $(-174 \mathrm{C} / \mathrm{G})]$ on hippocampal morphology. The IL6 genotype effect was found lateralized to the right. However, at a more lenient uncorrected statistical threshold, a similar genotype effect in the same direction could also be detected in the left hippocampus ( $p=0.007$, uncorrected, in the allele-dose model). Therefore, we discuss the observed effects for the hippocampus in general. The other investigated three SNPs showed no significant association with gray matter volume in our study. Since the SNPs 2069840 has been related to reduced IL-6 plasma levels, the lack of association in our study can be interpreted as consistent with the assumption that reduced plasma levels do not exert neuroplastic, neuroproliferative, or neuroprotective effects. In contrast, the marker rs1800796 showed no association with gray matter volume in our study, although, in a previous study, the $\mathrm{G}$ allele of this SNP has also been associated with 

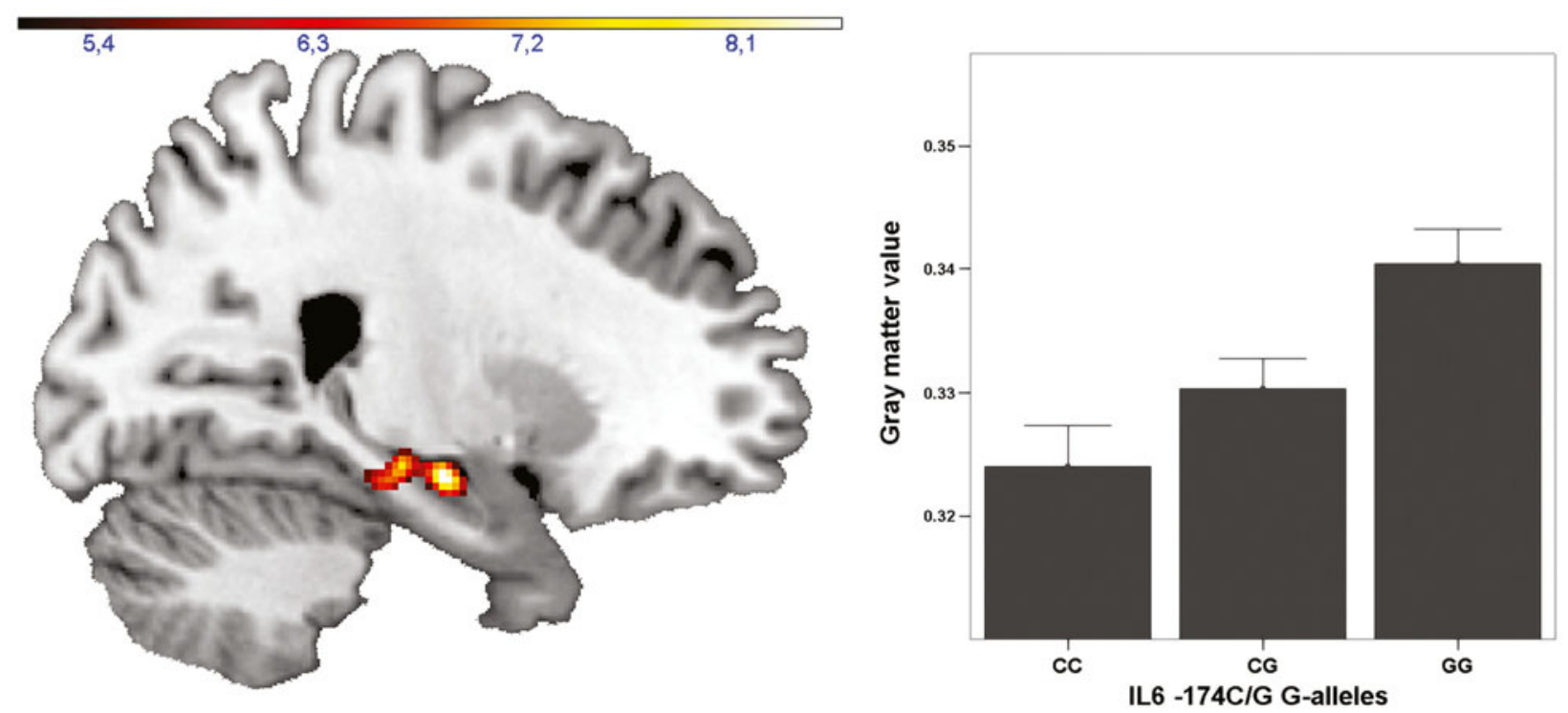

Figure 1 Effect of IL-6 rs1800795 (-174 C/G) genotype on brain morphometry. Left panel: Sagittal view through the right hippocampus $(x=24)$ depicting gray matter volume significantly modulated by the $I L-6-174 \mathrm{C} / \mathrm{G}$ genotype, thresholded at $p<0.005, \mathrm{k}=340$ (corresponding to $p<0.05$, corrected on the cluster level for the entire brain), adjusted for age, education and gender. Color bar, F-value ( $\mathrm{df}=2,286)$; Right panel: Bar graph depicting gray matter concentration at $x=21, y=-12, z=-15$ dependent on IL-6 -174 C/G genotype.

higher IL-6 plasma levels [40]. Since these findings were derived from a clinical cohort of patients with diabetic nephropathy without data on brain morphometry, a direct comparison with our study is precluded.

Our study shows the strongest association between the IL-6 genetic variant and $\mathrm{HC}$ volume, which has a number of critical functions under healthy and pathological conditions. It is part of a brain network including the dorsomedial and dorsolateral prefrontal cortex, the anterior cingulate cortex, and the amygdala dysregulated in major depression [61]. The HC is central to memory impairment, as seen in non-clinical samples [62] as well as in MDD [63]. Because the $\mathrm{HC}$ is a highly stress-sensitive brain region [64] and stress (psychological or psychosocial stress) is related to structural changes in the $\mathrm{HC}$ [65-67], atrophy of the $\mathrm{HC}$ has been described in imaging studies as a pathological neurobiological feature of depression associated with stress [68]. A meta-analysis of hippocampal volumes in patients with MDD confirmed that patients had hippocampal volumes approximately $4-6 \%$ smaller than matched control subjects in the left and right $\mathrm{HC}[69,70]$.

Although the possible role of IL-6 in brain morphology has not been extensively studied yet, our findings are in contrast with previous reports. These show associations between increased IL-6 plasma levels and reduced hippocampal volume in a relatively small study $(N=76)$ of middle-aged, relatively healthy individuals [16] in a study on first-episode psychosis [71], and in two studies investigating various brain areas and total brain volume, respectively, during aging [72,73]. Except in one study in relatively healthy individuals, these previous studies investigated individuals with underlying neuropsychiatric conditions. Variation in findings between these studies may be due to other methodological differences, such as the location of gray matter volume changes. While volume changes were located in the left $\mathrm{HC}$ in the study by Marsland et al. [16], and in various brain areas and total brain volume in the abovementioned studies on aging [72,73], our results were specific to the HC. Another important difference between studies is the biological model of IL- 6 effects in the brain. While those previous studies explain their findings using an inflammatory model in which it is proposed that IL-6 plays a proinflammatory role, the explanation of our study builds on the proven antiinflammatory and immunosuppressive effects of IL-6 according to the well-established dual role of IL-6 [74]. A possible mechanistic explanation to support our finding that IL-6 was associated with increased $\mathrm{HC}$ volumes relates to the previously reported neuroproliferative effects of IL-6. For example, it has been shown that cytokines, including IL-6, despite being large molecules not freely passing through the blood-brain barrier, can enter the brain via various pathways (humoral, cellular, neural) [75] to exert their biological effects in the brain even under physiological conditions. More specifically, it has been shown that IL- 6 primarily exerts its biological effects through a hexameric receptor ligand complex including the gp130 receptor [11] and the IL-6 receptor 
[76]. Distinct regions of gp130 activate specific signaltransduction pathways, such as the Janus kinase (JAK) signal transducer and activator of transcription (STAT), mitogen-activated protein kinase (MAPK)/cAMP responsive element-binding protein (CREB), Ras-MAPK, and PI-3 kinase (for review [77]). These pathways are related to neural plasticity by their ability to induce processes of neurogenesis, such as gliogenesis, neuronal differentiation, cAMP response element binding (cAMP), neural progenitor proliferation, and neuronal survival [77-79], and to enhance synaptic plasticity, LTP, and memory consolidation [33-35]. Through activation of these pathways, IL- 6 has the ability to exert neuroprotective and neuroproliferative effects. In addition, IL-6 has been found to regulate survival of differentiated neurons and the development of astrocytes [36,37]. Some in-vitro studies show IL- 6 release by activated microglia is a key inhibitor of neurogenesis by approximately 50\%; others show IL-6 promoting differentiation of neural stem cells (NSCs) [10,80-82]. NSCs derived from rodent spinal cord show that IL- 6 induces NSC proliferation via the JAK2/STAT3 and MAPK pathways [83]. Supporting a role of IL-6 in neuroproliferation is an in-vivo study showing that IL- 6 knockout mice have reduced proliferating NSCs specifically in the $\mathrm{HC}$, hence underlining the importance of IL-6 in cell proliferation and cell survival [84].

Despite mechanistic evidence and studies in humans for both pro- and anti-inflammatory effects of IL-6 in the brain, the role of IL- 6 in the hippocampus remains to be clarified. Specifically, it is questionable that increased levels of IL-6 have purely degenerative effects since proliferative effects of IL-6 in the HC were demonstrated in an exercise study in mice: a wheel-running study in mice over 16 weeks showed that exercise increased IL-6 levels in the $\mathrm{HC}$, whereas other cytokines such as TNF and IL-1ra decreased during exercise [85]. These results suggest that an upregulation of IL-6 could have anti-inflammatory effects and be neuroprotective in the cytokine milieu of the $\mathrm{HC}$, and thereby IL-6 may buffer cognitive decline through exercise-induced changes in the $\mathrm{HC}$ milieu.

Translating these findings into a human study, one could argue that peripherally increased IL-6 levels could be interpreted as an anti-inflammatory activity rather than a proinflammatory state. Hence, previously observed correlations between increased plasma levels of IL- 6 and decreased $\mathrm{HC}$ volumes could alternatively be interpreted as an anti-inflammatory response of IL-6 to other increased cytokines such as TNF and IL-1beta. Indeed, both cytokines have previously been shown to be associated with hippocampal volumes (TNF) [86] and with increased white matter hyperintensities (IL-1beta) [87] in healthy individuals. In such a case, IL- 6 would only be a marker of a global inflammatory process, and reduced brain volume might primarily be induced by proinflammatory cytokines such as TNF and IL1-beta.

In light of these studies suggesting effects of IL-6 on various mechanisms subserving neuroproliferation and assuming that the carriers of the G-allele of the $I L-6$ polymorphism rs1800795 $(-174 \mathrm{C} / \mathrm{G})$ in our sample have increased IL-6 levels as previously reported, it can be suggested that in our imaging study, this particular SNP might exert neuroprotective effects on the $\mathrm{HC}$ via increased IL-6 levels, hence the observed increased gray matter volume.

Our study has strengths and limitations. We were able to employ the genetic analysis in a large imaging sample using a cohort of carefully selected and wellcharacterized healthy individuals. For future studies, clinical measures such as hypertension or BMI could be useful covariates when investigating genetic inflammatory biomarkers such as IL-6; however, the relevance of hypertension might be of greater relevance in clinical samples than in our healthy cohort. Our discussion is based on the assumption that larger gray matter values in the hippocampus correspond to better function. Albeit reduced hippocampal volumes are consistently found in neuropsychiatric disorders, the relation of volume and function remains to be established more firmly. Although no protein data were available to validate the well-described upregulation of IL-6 by the SNP rs1800795 $(-174 \mathrm{C} / \mathrm{G})$, our study is the first genetic study investigating the association between the $I L-6$ gene and brain morphometry, and the $\mathrm{HC}$ in particular. Future genetic imaging studies would benefit from additional protein data. Moreover, a clinical control group with a psychiatric disorder such as depression or psychosis/schizophrenia might add knowledge on the dual role of the $I L-6$ gene in health and disease states. Another important consideration for interpreting these results is related to the lack of a cutoff of level of IL-6 defining normal, increased, and decreased peripheral IL6 levels, limiting the interpretation of physiological and pathological brain conditions. The LD indices indicate complete $\operatorname{LD}\left(D^{\prime}=1\right)$ for the correlation of all four marker combinations (except $D^{\prime}=0.993$ for rs1800795 $\mathrm{x}$ rs2069833), which indicates that the reported findings are not explained by relevant SNP correlations.

\section{Conclusion}

This imaging genetic study suggests the $I L-6$ genetic variant rs1800795 (-174 C/G) as a biomarker of hippocampal morphometry. This genetic variant may exert neuroprotective effects on hippocampal volume in healthy individuals. Replication in independent and clinical samples is warranted. 


\section{Acknowledgements}

The study was supported by grants of Innovative Medizinische Forschung (IMF) of the Medical Faculty of Münster (IMF DA120309 to UD, IMF DA211012 to UD, IMF DA111107 to UD, and IMF AR510403 to VA), Interdisziplinäres Zentrum für Klinische Forschung (IZKF) of the Medical Faculty of Münster (IZKF FG04 to CK), and Rolf-Dierichs-Stiftung (ZUW80037 to UD), Germany.

\section{Author details}

${ }^{1}$ Discipline of Psychiatry, School of Medicine, University of Adelaide, North Terrace, Adelaide, South Australia 5005, Australia. ${ }^{2}$ Department of Psychiatry, University of Marburg, Marburg, Germany. ${ }^{3}$ Department of Psychiatry, University of Muenster, Muenster, Germany. ${ }^{4}$ Department of Psychiatry, Psychosomatics and Psychotherapy, University of Wuerzburg, Wuerzburg, Germany. ${ }^{5}$ Department of Psychosomatic Medicine and Psychotherapy, University of Leipzig, Leipzig, Germany. ${ }^{6}$ Supramolecular and Synthetic Biology Group, School of Pharmacy and Molecular Sciences, James Cook University, Brisbane, QLD, Australia. 'Department of Clinical Radiology, University of Muenster, Muenster, Germany.

\section{Competing of interests}

KD has received speaker fees from Pfizer, Lilly, and Bristol-Myers Squibb; she has been a consultant for Johnson \& Johnson and has received funding by Astra Zeneca. All other authors declare no conflicts of interest.

\section{Authors' contributions}

BTB conceived and proposed the genetic analysis, and wrote the first draft together with UD. UD performed the imaging and imaging-genetics analysis, and drafted parts of the manuscript. CK contributed to the design of the study, oversaw recruitment of participants, and contributed to the draft manuscript. DG contributed to the recruitment and assessment of participants. TS contributed to the study design and the interpretation of the results. EB contributed to the genetic analyses of the results. PO, SS, AV, and $\mathrm{CU}$ carried out the recruitment, assessment, and measurements of participants. WH, JB, and HK oversaw and conducted the imaging MRI component of the study. KD contributed to data of participants, and oversaw DNA collection and contributed intellectually to a draft of the manuscript. VA contributed intellectually to the content of the manuscript. UD oversaw, conceived the imaging study, and contributed to the writing of the MS. All authors contributed intellectually to the manuscripts and approved the final versions of the manuscript.

Received: 30 March 2012 Accepted: 13 June 2012

Published: 13 June 2012

\section{References}

1. Dowlati Y, Herrmann N, Swardfager W, Liu H, Sham L, Reim EK, Lanctot KL: A meta-analysis of cytokines in major depression. Biol Psychiatry 2010, 67:446-457.

2. Tancredi V, D'Antuono M, Cafe C, Giovedi S, Bue MC, D'Arcangelo G, Onofri $F$, Benfenati $F$ : The inhibitory effects of interleukin- 6 on synaptic plasticity in the rat hippocampus are associated with an inhibition of mitogenactivated protein kinase ERK. J Neurochem 2000, 75:634-643.

3. Hannestad J, DellaGioia N, Bloch M: The effect of antidepressant medication treatment on serum levels of inflammatory cytokines: a meta-analysis. Neuropsychopharmacology 2011, 36:2452-2459.

4. Morales I, Farias G, Maccioni RB: Neuroimmunomodulation in the pathogenesis of Alzheimer's disease. Neuroimmunomodulation 2010, 17:202-204.

5. Kim JM, Stewart R, Kim SW, Shin IS, Kim JT, Park MS, Park SW, Kim YH: Cho $\mathrm{KH}$. Yoon JS: Associations of cytokine gene polymorphisms with post-stroke depression. World J Biol Psychiatry; 2011.

6. McAfoose J, Baune BT: Evidence for a cytokine model of cognitive function. Neurosci Biobehav Rev 2009, 33:355-366.

7. Baune BT, Rothermundt M, Ladwig KH, Meisinger C, Berger K: Systemic inflammation (Interleukin 6) predicts all-cause mortality in men: results from a 9-year follow-up of the MEMO Study. Age (Dordr) 2011, 33:209-217.

8. Heneka MT, O'Banion MK, Terwel D, Kummer MP: Neuroinflammatory processes in Alzheimer's disease. J Neural Transm 2010, 117:919-947.
9. Miller $\mathrm{AH}$, Maletic $\mathrm{V}$, Raison $\mathrm{CL}$ : Inflammation and its discontents: the role of cytokines in the pathophysiology of major depression. Biol Psychiatry 2009, 65:732-741.

10. Vallieres L, Campbell IL, Gage FH, Sawchenko PE: Reduced hippocampal neurogenesis in adult transgenic mice with chronic astrocytic production of interleukin-6. J Neurosci 2002, 22:486-492.

11. Peng YP, Qiu YH, Lu JH, Wang JJ: Interleukin-6 protects cultured cerebellar granule neurons against glutamate-induced neurotoxicity. Neurosci Lett 2005, 374:192-196.

12. Godbout JP, Johnson RW: Interleukin-6 in the aging brain. J Neuroimmunol 2004, 147:141-144

13. Brietzke E, Stertz L, Fernandes BS, Kauer-Sant'anna M, Mascarenhas M, Escosteguy Vargas A, Chies JA, Kapczinski F: Comparison of cytokine levels in depressed, manic and euthymic patients with bipolar disorder. J Affect Disord 2009, 116:214-217.

14. Angelopoulos P, Agouridaki H, Vaiopoulos H, Siskou E, Doutsou K, Costa V, Baloyiannis SI: Cytokines in Alzheimer's disease and vascular dementia. Int J Neurosci 2008, 118:1659-1672.

15. Baune BT, Ponath G, Rothermundt M, Roesler A, Berger K: Association between cytokines and cerebral MRI changes in the aging brain. J Geriatr Psychiatry Neurol 2009, 22:23-34.

16. Marsland AL, Gianaros PJ, Abramowitch SM, Manuck SB, Hariri AR: Interleukin-6 covaries inversely with hippocampal grey matter volume in middle-aged adults. Biol Psychiatry 2008, 64:484-490.

17. Tilg H, Dinarello CA, Mier JW: IL-6 and APPs: anti-inflammatory and immunosuppressive mediators. Immunol Today 1997, 18:428-432.

18. Gadient RA, Otten U: Expression of interleukin-6 (IL-6) and interleukin-6 receptor (IL-6R) mRNAs in rat brain during postnatal development. Brain Res 1994, 637:10-14.

19. Wagner JA: Is IL-6 both a cytokine and a neurotrophic factor? J Exp Med 1996, 183:2417-2419.

20. Akaneya $\mathrm{Y}$, Takahashi M, Hatanaka H: Interleukin-1 beta enhances survival and interleukin- 6 protects against MPP + neurotoxicity in cultures of fetal rat dopaminergic neurons. Exp Neurol 1995, 136:44-52.

21. Hama T, Kushima Y, Miyamoto M, Kubota M, Takei N, Hatanaka H: Interleukin-6 improves the survival of mesencephalic catecholaminergic and septal cholinergic neurons from postnatal, two-week-old rats in cultures. Neuroscience 1991, 40:445-452.

22. Hama T, Miyamoto M, Tsukui H, Nishio C, Hatanaka H: Interleukin-6 as a neurotrophic factor for promoting the survival of cultured basal forebrain cholinergic neurons from postnatal rats. Neurosci Lett 1989, 104:340-344.

23. Kushima Y, Hama T, Hatanaka H: Interleukin-6 as a neurotrophic factor for promoting the survival of cultured catecholaminergic neurons in a chemically defined medium from fetal and postnatal rat midbrains. Neurosci Res 1992, 13:267-280.

24. Kushima Y, Hatanaka H: Interleukin-6 and leukemia inhibitory factor promote the survival of acetylcholinesterase-positive neurons in culture from embryonic rat spinal cord. Neurosci Lett 1992, 143:110-114.

25. Loddick SA, Turnbull AV, Rothwell NJ: Cerebral interleukin-6 is neuroprotective during permanent focal cerebral ischemia in the rat. $J$ Cereb Blood Flow Metab 1998, 18:176-179.

26. Matsuda S, Wen TC, Morita F, Otsuka H, Igase K, Yoshimura H, Sakanaka M: Interleukin-6 prevents ischemia-induced learning disability and neuronal and synaptic loss in gerbils. Neurosci Lett 1996, 204:109-112.

27. Toulmond S, Vige X, Fage D, Benavides J: Local infusion of interleukin-6 attenuates the neurotoxic effects of NMDA on rat striatal cholinergic neurons. Neurosci Lett 1992, 144:49-52.

28. Yamada $M$, Hatanaka $H$ : Interleukin-6 protects cultured rat hippocampal neurons against glutamate-induced cell death. Brain Res 1994, 643:173-180.

29. Wu YY, Bradshaw RA: Induction of neurite outgrowth by interleukin- 6 is accompanied by activation of Stat3 signaling pathway in a variant PC12 cell (E2) line. J Biol Chem 1996, 271:13023-13032.

30. Gadient RA, Otten UH: Interleukin-6 (IL-6)-a molecule with both beneficial and destructive potentials. Prog Neurobiol 1997, 52:379-390.

31. Ihara S, Iwamatsu A, Fujiyoshi T, Komi A, Yamori T, Fukui Y: Identification of interleukin- 6 as a factor that induces neurite outgrowth by PC12 cells primed with NGF. J Biochem 1996, 120:865-868.

32. Ihara S, Nakajima K, Fukada T, Hibi M, Nagata S, Hirano T, Fukui Y: Dual control of neurite outgrowth by STAT3 and MAP kinase in PC12 cells stimulated with interleukin-6. EMBO J 1997, 16:5345-5352. 
33. Pickering $\mathrm{M}, \mathrm{O}^{\prime} \mathrm{C}$ onnor Jj: Pro-inflammatory cytokines and their effects in the dentate gyrus. Prog Brain Res 2007, 163:339-354

34. Vitkovic L, Konsman JP, Bockaert J, Dantzer R, Homburger V, Jacque C Cytokine signals propagate through the brain. Mol Psychiatry 2000, 5:604-615.

35. Viviani B, Gardoni F, Marinovich M: Cytokines and neuronal ion channels in health and disease. Int Rev Neurobiol 2007, 82:247-263.

36. Kahn MA, De Vellis J: Regulation of an oligodendrocyte progenitor cell line by the interleukin-6 family of cytokines. Glia 1994, 12:87-98.

37. Murphy M, Dutton R, Koblar S, Cheema S, Bartlett P: Cytokines which signal through the LIF receptor and their actions in the nervous system. Prog Neurobiol 1997, 52:355-378.

38. Bonafe M, Olivieri F, Cavallone L, Giovagnetti S, Mayegiani F, Cardelli M, Pieri C, Marra M, Antonicelli R, Lisa R, et al: A gender-dependent genetic predisposition to produce high levels of IL- 6 is detrimental for longevity. Eur J Immunol 2001, 31:2357-2361.

39. Christiansen L, Bathum L, Andersen-Ranberg K, Jeune B, Christensen K. Modest implication of interleukin- 6 promoter polymorphisms in longevity. Mech Ageing Dev 2004, 125:391-395.

40. Kitamura A, Hasegawa G, Obayashi H, Kamiuchi K, Ishii M, Yano M, Tanaka T, Yamaguchi M, Shigeta $\mathrm{H}$, Ogata M, et al: Interleukin-6 polymorphism $(-634 \mathrm{C} / \mathrm{G})$ in the promotor region and the progression of diabetic nephropathy in type 2 diabetes. Diabet Med 2002, 19:1000-1005

41. Terry CF, Loukaci V, Green FR: Cooperative influence of genetic polymorphisms on interleukin 6 transcriptional regulation. J Biol Chem 2000, 275:18138-18144.

42. MacQueen GM, Frodl T: The hippocampus in major depression: Evidence for the convergence of the bench and bedside in psychiatric research? Mol Psychiatry 2010, 16:252-264.

43. Kasai K, Yamasue H, Gilbertson MW, Shenton ME, Rauch SL, Pitman RK: Evidence for acquired pregenual anterior cingulate gray matter loss from a twin study of combat-related posttraumatic stress disorder. Biol Psychiatry 2008, 63:550-556.

44. Dannlowski U, Stuhrmann A, Beutelmann V, Zwanzger $P$, Lenzen T, Grotegerd D, Domschke K, Hohoff C, Ohrmann P, Bauer J, et al: Limbic Scars: Long-Term Consequences of Childhood Maltreatment Revealed by Functional and Structural Magnetic Resonance Imaging. Biol Psychiatry 2012 Feb 15, 71(4):286-293.

45. American Psychiatric Association: Diagnostic and Statistical Manual of Mental Disorders. 4th edition. Washington, DC: American Psychiatric Association; 1994.

46. Wittchen H-U, Wunderlich U, Gruschwitz S, Zaudig M: SKID-I. Strukturiertes Klinisches Interview für DSM-IV. Göttingen: Hogrefe; 1997

47. Beck AT, Steer RA: Beck Depression Inventory: manual. San Antonio: Psychological Corporation Harcourt Brace Jovanovich; 1987.

48. Lehrl S: Mehrfachwahl-Wortschatz-Intelligenztest MWT-B. Göttingen: Hogrefe 1995.

49. Carlson CS, Reider MJ, Nickerson DA, Eberle MA, Kruglyak L: Comment on 'Discrepancies in dbSNP confirmations rates and allele frequency distributions from varying genotyping error rates and patterns'. Bioinformatics 2005, 21:141-143.

50. HapMap I, HapMap, Consortium: A haplotype map of the human genome. Nature 2005, 437:1299-1320.

51. Davidovich O, Kimmel G, Shamir R: GEVALT: An integrated software tool for genotype analysis. BMC Bioinformatics 2007, 8:36.

52. Halperin E, Kimmel G, Shamir R: Tag SNP selection in genotype data for maximizing SNP prediction accuracy. Bioinformatics 2005, 21:i195-i203.

53. Pierce BL, Biggs ML, DeCambre M, Reiner AP, Li C, Fitzpatrick A, Carlson CS, Stanford JL, Austin MA: C-reactive protein, interleukin-6, and prostate cancer risk in men aged 65 years and older. Cancer Causes Control 2009, 20:1193-1203.

54. Sousa AL, Fava VM, Sampaio LH, Martelli CM, Costa MB, Mira MT, Stefani MM: Genetic and immunological evidence implicates interleukin 6 as a susceptibility gene for leprosy type 2 reaction. J Infect Dis 2012, 205:1417-1424.

55. Oeth P, Beaulieu M, Park C, Kosman D: iPLEX Assay: Increased Plexing Efficiency and Flexibility for MassARRAY System Through Single Base Primer Extension with Mass-Modified Terminators.; 2007. Available at: http://www. agrf.org.au/docstore/snp/iPlex.pdf. Accessed December 12, 2011

56. Ashburner J, Friston KJ: Unified segmentation. Neuroimage $2005 \mathrm{Jul} 1$, 26(3):839-851.
57. Forman SD, Cohen JD, Fitzgerald M, Eddy WF, Mintun MA, Noll DC: Improved assessment of significant activation in functional magnetic resonance imaging (fMRI): use of a cluster-size threshold. Magnetic resonance in medicine: official journal of the Society of Magnetic Resonance in Medicine/Society of Magnetic Resonance in Medicine 1995, 33:636-647.

58. Tzourio-Mazoyer N, Landeau B, Papathanassiou D, Crivello F, Etard O, Delcroix N, Mazoyer B, Joliot M: Automated anatomical labeling of activations in SPM using a macroscopic anatomical parcellation of the MNI MRI single-subject brain. Neuroimage 2002, 15:273-289.

59. Eickhoff S, Stephan KE, Mohlberg H, Grefkes C, Fink GR, Amunts K, Zilles K: A new SPM toolbox for combining probabilistic cytoarchitectonic maps and functional imaging data. Neuroimage 2005, 25:1325-1335.

60. Faul F, Erdfelder E, Lang AG, Buchner A: G*Power 3: a flexible statistical power analysis program for the social, behavioral, and biomedical sciences. Behav Res Methods 2007, 39:175-191.

61. Frodl T, Bokde AL, Scheuerecker J, Lisiecka D, Schoepf V, Hampel H, Moller $\mathrm{HJ}$, Bruckmann $\mathrm{H}$, Wiesmann M, Meisenzahl E: Functional connectivity bias of the orbitofrontal cortex in drug-free patients with major depression. Biol Psychiatry 2010, 67:161-167.

62. Gatt JM, Nemeroff CB, Dobson-Stone C, Paul RH, Bryant RA, Schofield PR, Gordon E, Kemp AH, Williams LM: Interactions between BDNF Val66Met polymorphism and early life stress predict brain and arousal pathways to syndromal depression and anxiety. Mol Psychiatry 2009, 14:681-695.

63. Beblo T, Sinnamon G, Baune BT: Specifying the neuropsychology of affective disorders: clinical, demographic and neurobiological factors. Neuropsychol Rev 2011, 21:337-359.

64. Thomas RM, Hotsenpiller G, Peterson DA: Acute psychosocial stress reduces cell survival in adult hippocampal neurogenesis without altering proliferation. J Neurosci 2007, 27:2734-2743.

65. Malberg JE, Duman RS: Cell proliferation in adult hippocampus is decreased by inescapable stress: reversal by fluoxetine treatment Neuropsychopharmacology 2003, 28:1562-1571.

66. Pham K, Nacher J, Hof PR, McEwen BS: Repeated restraint stress suppresses neurogenesis and induces biphasic PSA-NCAM expression in the adult rat dentate gyrus. Eur J Neurosci 2003, 17:879-886.

67. Vermetten E, Bremner JD: Circuits and systems in stress. I. Preclinical studies. Depress Anxiety 2002, 15:126-147.

68. Hickie I, Naismith S, Ward PB, Turner K, Scott E, Mitchell P, Wilhelm K, Parker $G$ : Reduced hippocampal volumes and memory loss in patients with early- and late-onset depression. Br J Psychiatry 2005, 186:197-202.

69. Campbell S, Marriott M, Nahmias C, MacQueen GM: Lower hippocampal volume in patients suffering from depression: a meta-analysis. Am J Psychiatry 2004, 161:598-607.

70. Videbech P, Ravnkilde B: Hippocampal volume and depression: a metaanalysis of MRI studies. Am J Psychiatry 2004 Nov, 161(11):1957-1966.

71. Mondelli V, Cattaneo A, Murri MB, Di Forti M, Handley R, Hepgul N, Miorelli A, Navari S, Papadopoulos AS, Aitchison KJ, Mondelli V, Cattaneo A, Murri MB, Di Forti M, Handley R, Hepgul N, Miorelli A, Navari S, Papadopoulos AS, Aitchison KJ, et al: Stress and inflammation reduce brain-derived neurotrophic factor expression in first-episode psychosis: a pathway to smaller hippocampal volume. J Clin Psychiatry 2011,

72. Willette AA, Bendlin BB, McLaren DG, Canu E, Kastman EK, Kosmatka KJ, Xu $G$, Field AS, Alexander AL, Colman RJ, et al: Age-related changes in neural volume and microstructure associated with interleukin- 6 are ameliorated by a calorie-restricted diet in old rhesus monkeys. Neuroimage 2010, 51:987-994.

73. Jefferson AL, Massaro JM, Wolf PA, Seshadri S, Au R, Vasan RS, Larson MG, Meigs JB, Keaney JF Jr: Lipinska I, et al: Inflammatory biomarkers are associated with total brain volume: the Framingham Heart Study. Neurology 2007, 68:1032-1038.

74. Munoz-Fernandez MA, Fresno M: The role of tumour necrosis factor, interleukin 6, interferon-gamma and inducible nitric oxide synthase in the development and pathology of the nervous system. Prog Neurobiol 1998, 56:307-340.

75. Capuron L, Miller AH: Immune system to brain signaling: neuropsychopharmacological implications. Pharmacol Ther 2011, 130:226-238.

76. Ward LD, Howlett GJ, Discolo G, Yasukawa K, Hammacher A, Moritz RL, Simpson RJ: High affinity interleukin- 6 receptor is a hexameric complex consisting of two molecules each of interleukin-6, interleukin-6 receptor, and gp-130. J Biol Chem 1994, 269:23286-23289. 
77. Islam O, Gong X, Rose-John S, Heese K: Interleukin-6 and neural stem cells: more than gliogenesis. Mol Biol Cell 2009, 20:188-199.

78. Hirano T, Nakajima K, Hibi M: Signaling mechanisms through gp130: a model of the cytokine system. Cytokine Growth Factor Rev 1997, 8:241-252.

79. Ohbayashi N, lkeda O, Taira N, Yamamoto Y, Muromoto R, Sekine Y, Sugiyama K, Honjoh T, Matsuda T: LIF- and IL-6-induced acetylation of STAT3 at Lys-685 through PI3K/Akt activation. Biol Pharm Bull 2007, 30:1860-1864.

80. Monje ML, Toda H, Palmer TD: Inflammatory blockade restores adult hippocampal neurogenesis. Science 2003, 302:1760-1765.

81. Oh J, McCloskey MA, Blong CC, Bendickson L, Nilsen-Hamilton M, Sakaguchi DS: Astrocyte-derived interleukin-6 promotes specific neuronal differentiation of neural progenitor cells from adult hippocampus. Neurosci Res 2010, 88:2798-2809.

82. Balasubramaniam B, Carter DA, Mayer EJ, Dick AD: Microglia derived IL-6 suppresses neurosphere generation from adult human retinal cell suspensions. Exp Eye Res 2009, 89:757-766.

83. Kang MK, Kang SK: Interleukin-6 induces proliferation in adult spinal cordderived neural progenitors via the JAK2/STAT3 pathway with EGFinduced MAPK phosphorylation. Cell Prolif 2008, 41:377-392.

84. Bowen KK, Dempsey RJ, Vemuganti R: Adult interleukin-6 knockout mice show compromised neurogenesis. Neuroreport 2011, 22:126-130.

85. Pervaiz N, Hoffman-Goetz L: Freewheel training alters mouse hippocampal cytokines. Int J Sports Med 2011, 32:889-895.

86. Baune BT, Konrad C, Grotegerd D, Suslow T, Ohrmann P, Bauer J, Arolt V, Heindel W, Domschke K, Kugel H, Dannlowski U: Tumor necrosis factor (TNF) gene variation predicts hippocampus volume in healthy individuals. Biol Psychiatry. in press.

87. Raz N, Yang Y, Dahle CL, Land S: Volume of white matter hyperintensities in healthy adults: contribution of age, vascular risk factors, and inflammation-related genetic variants. Biochim Biophys Acta 2012, 1822:361-369

doi:10.1186/1742-2094-9-125

Cite this article as: Baune et al: Interleukin- 6 gene (IL-6): a possible role in brain morphology in the healthy adult brain. Journal of Neuroinflammation 2012 9:125.

\section{Submit your next manuscript to BioMed Central and take full advantage of:}

- Convenient online submission

- Thorough peer review

- No space constraints or color figure charges

- Immediate publication on acceptance

- Inclusion in PubMed, CAS, Scopus and Google Scholar

- Research which is freely available for redistribution 